\title{
Introduction to series on robotic adrenalectomy
}

\author{
'When setting out on a journey, do not seek advice from those who have never left home...'___ Jalaladdin Rumi
}

Since its introduction more than 30 years ago, endoscopic surgery has become the gold standard approaches to adrenal surgery for adrenal pathologies. Meanwhile, the indications for adrenal surgery have been continuously extended in the last decades, worldwide. From a surgical point of view, recently we face an evolvement of minimally invasive surgery, leading to robotic surgery. Piazza et al. (1) and Hubens et al. (2) reported the first cases of robot-assisted adrenalectomy using the Zeus AESOP (Computer Motion, Inc., Santa Barbara, CA, USA) in 1999. After the introduction of the da Vinci system (Intuitive Surgical, Sunnyvale, CA, USA), several series of robotic surgical procedures, including adrenalectomies have been reported. With the increased use of robotics in surgery, robotic adrenalectomy has been adopted by many high-volume tertiary centers as a good alternative treatment to conventional laparoscopic adrenalectomy. The widespread diffusion of robotic technology has led to the development and standardization of robot-assisted approach to adrenalectomy (3). This has also reflected to the increase of paper production regarding this specific topic.

As surgeons, we are happy to face the advances in robotic technology. Whether this technology will serve the best to our patients is still a matter of debate. Herein, we tried to answer this question. In this context, I am very thankful to all experts in the field, who have been involved in this issue dedicated to 'robotic adrenal surgery'. This issue serves with one multicenter clinical trial and seven reviews.

The trial investigated outcomes of robotic adrenalectomy cases from two high-volume endocrine surgery centers. Whether number of surgeries and increased experience had an effect on complication rates also was assessed. Identification of risk factors for complications after robotic adrenalectomy is given value in this issue. Authors analyzed seven principal risk factors for complication: BMI, age, tumor size, tumor side, pathology, previous surgery and surgeon's experience. From this review we can affirm that some studies identify the tumor size, the malignancy, a learning curve not completed and, less clearly, previous ipsilateral upper mesocolic or retroperitoneal surgery as risk factors for postoperative complications and for failure of the robotic approach.

With more than 3,500 robotic units for surgery, United States is dominating the robotic market in the World. Market factors, clinical factors and surgeon factors all play a role in the spread and adoption of robotic surgery in general. The most up to date literature on the state of robotic adrenalectomy in the United States is reviewed and some factors that may be influencing the rate of adoption of robotic adrenalectomy in the United States are explored.

Cost increase still represents a major drawback correlated to robotic surgery (4). In this issue, authors express that despite the higher cost, robotic adrenalectomy appears to be cost-effective and sustainable in a DRG-based reimbursement system. If reserved to larger and more challenging adrenal pathologies, for which more benefits are expected by robotic adrenalectomy, the cost-effectiveness increases, and the differences with other techniques significantly may reduce.

There is a lack of articles when specifically addressing the subject on adrenalectomies for patients with pheochromocytomas. Adrenalectomy is the gold standard treatment of pheochromocytomas. Herein, all available studies evaluating the use of the robotic system to perform an adrenalectomy when treating patients with pheochromocytoma have been reviewed systematically.

Single incision robotic surgeries have become more common and they have been increasingly used for several surgeries including adrenalectomy. Authors review the properties of single incision robotic adrenalectomy, including perioperative results, patient selection, learning curve, cost-effectiveness and its limitations as well as newly emerging single incision technologies. In this review, the recent FDA approved Da Vinci Single Port system is also discussed.

The use of indocyanine green (ICG) has several outstanding advantages during adrenal gland surgery. There are a few publications regarding the feasibility of ICG use for robotic adrenal surgery. ICG-enhanced fluorescence-guided imaging is a potentially useful technique that has the potential to enhance the surgeon performance. Authors review the specific advantages of ICG use.

In recent years, the drive behind the general trend toward minimally invasive procedures represents the result of a diverse combination of factors, primarily the obvious drawbacks of almost any surgical intervention, the development and refinement 
of new technologies, the aim to reduce peri-operative complications and post-operative recovery time especially in subjects debilitated or who refuse surgery, and patient awareness of emerging therapeutic approaches. Authors analyze the current evidence on image-guided ablative procedures for adrenal neoplasms in terms of safety and outcomes.

The expectation is that, with the increasing number of robotic units per country, in coming years robotic surgery 'drylab' \& 'wet-lab' training will be offered to all surgical residents and expressed officially in their curriculum. The papers you will find in this issue may also stimulate some interest of young surgeons to become involved in robotic adrenal surgery. Those interested may engage in future educational events organized by the European Society of Endocrine Surgeons (ESES). This call-out was given previously by Radu Mihai (5). The society has established the fean-Francois Henry Travelling Fellowship (http://www.eses.cc/jfh-travelling-scholarship.html) with the aim of supporting trainees who want to visit a center of excellence to learn a new technique and see in practice many of the technical issues, including robotic surgery. Honored and pleased by the invitation to manage the 'robotic adrenalectomy' issue as 'guest editor' for Gland Surgery, I want to thank once again all my experienced friends who accepted the invitation for sharing their work.

\section{Acknowledgments}

Funding: None.

\section{Footnote}

Provenance and Peer Review: This article was commissioned by the editorial office, Gland Surgery for the series "Robotic Adrenalectomy". The article did not undergo external peer review.

Conflicts of Interest: The author has completed the ICMJE uniform disclosure form (available at http://dx.doi.org/10.21037/ gs-2019-ra-09). The series "Robotic Adrenalectomy" was commissioned by the editorial office without any funding or sponsorship. OZ served as the unpaid Guest Editor for the series and serves as an unpaid editorial board member of Gland Surgery from May 2019 to Apr 2021.

Ethical Statement: The author is accountable for all aspects of the work in ensuring that questions related to the accuracy or integrity of any part of the work are appropriately investigated and resolved.

Open Access Statement: This is an Open Access article distributed in accordance with the Creative Commons AttributionNonCommercial-NoDerivs 4.0 International License (CC BY-NC-ND 4.0), which permits the non-commercial replication and distribution of the article with the strict proviso that no changes or edits are made and the original work is properly cited (including links to both the formal publication through the relevant DOI and the license). See: https://creativecommons.org/licenses/by-ncnd/4.0/.

\section{References}

1. Piazza L, Caragliano P, Scardilli M, et al. Laparoscopic robot-assisted right adrenalectomy and left ovariectomy (case reports). Chir Ital 1999;51:465-6.

2. Hubens G, Ysebaert D, Vaneerdeweg W, et al. Laparoscopic adrenalectomy with the aid of the AESOP 2000 robot. Acta Chir Belg 1999;99:125-7.

3. Desai MM, Gill IS, Kaouk JH, et al. Robotic-assisted laparoscopic adrenalectomy. Urology 2002;60:1104-7.

4. Economopoulos KP, Mylonas K, Stamou AA, et al. Laparoscopic versus robotic adrenalectomy: a comprehensive metaanalysis. Int J Surg 2017;38:95-104.

5. Mihai R. Surgical anatomy of the adrenal gland. Gland Surg 2019;8:S1-S2. 


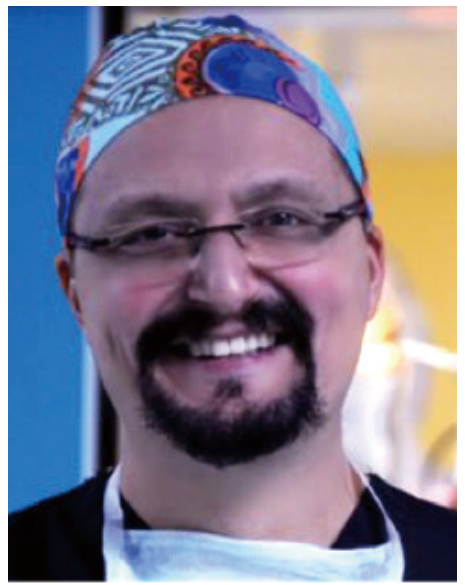

Özer Makay

\section{Özer Makay}

Professor of Surgery, Division of Endocrine Surgery, Department of Surgery, Ege University Hospital, Izmir, Turkey.

(Email: ozer.makay@ege.edu.tr)

Submitted Apr 16, 2020. Accepted for publication Apr 30, 2020.

doi: $10.21037 / \mathrm{gs}-2019-\mathrm{ra}-09$

View this article at: http://dx.doi.org/10.21037/gs-2019-ra-09

Cite this article as: Makay Ö. Introduction to series on robotic adrenalectomy. Gland Surg 2020;9(3):812-814. doi: 10.21037/gs2019-ra-09 